\title{
Effect of Ginger-Naproxen on Knee Osteoarthritis: A Clinical Study
}

\author{
Mehtab Munir, Khalid Mustafa Memon, Sajid Abbas Jaffri, Hasan Ali
}

Objective: To evaluate clinical efficacy and safety of ginger with naproxen, in treating knee osteoarthritis.

Study design and setting: Randomized clinical trial conducted in medicine department OPD of National Medical Center, Karachi from $21^{\text {st }}$ September 2018 till $31^{\text {st }}$ March 2019.

Methodology: This study was conducted on 60 patients of knee osteoarthritis. After written informed consent, the patients were randomized to two groups. Group A received tablet naproxen 500mg and capsule ginger 550mg, twice daily and group B was given tablet naproxen 500mg twice daily. Total 53 patients finished the study (group A: $n=27$ and group B: $n=26$ ). Baseline pain (Visual Analogue Scale) and Western Ontario and McMaster Universities Osteoarthritis index (WOMAC) scores were noted at the beginning of study and reassessed after 6 weeks of the intervention. Safety profile of the drugs was assessed by observing adverse effects. Independent t-test was applied to check difference between the two groups. Statistical analysis was performed using SPSS version 23.0. P-value $<0.05$ was considered as statistically significant.

Results: Before the intervention no significant difference was observed in two groups. However significant difference was observed between the groups in pain $(\mathrm{p}=0.019)$ and WOMAC $(\mathrm{p}=0.020)$ scores after 6 weeks of intervention. Moreover there was no significant difference $(\mathrm{p}=0.914)$ in occurrence of adverse effects between the two groups at the end of 6 weeks of study.

Conclusion: Ginger with naproxen can effectively treat pain and stiffness in knee osteoarthritis without added adverse effects when compared with naproxen alone.

Key words: Ginger, Knee osteoarthritis, Naproxen, Pain, Stiffness, WOMAC score.

How to cite this Article:

Munir M, Memon KM, Jaffri SA, Ali H. Effect of Ginger-Naproxen on Knee Osteoarthritis: A Clinical Study. J Bahria Uni Med Dental Coll. 2021; 11(1):17-21 DOI: https://doi.org/10.51985/FAGQ7533

- - - - - - - - - - - - - - - - - - - - - - - - - - - - - -

This is an Open Access article distributed under the terms of the Creative Commons Attriution Non Commercial Liciense (http:// creativecommons/org/licences/by-nc/4.0) which permits unrestricted non commercial use, distribution and reproduction in any medium, provided the original work is properly cited.

\section{INTRODUCTION:}

Osteoarthritis (OA) is an inflammatory and degenerative disease of joints. Most frequently, hand and weight bearing joints are affected. It is marked by the breakdown of the cartilage; this causes bones to rub against each other, causing pain and loss of movement. ${ }^{1}$ Globally $9.61 \%$ of men and $18.0 \%$ of women, greater than 60 years of age have symptomatic osteoarthritis as claimed by WHO. ${ }^{2}$ Prevalence of OA in Northern area of Pakistan was established to be $37 / 1000$ and there was preponderance of knee joint involvement that is $95 \%$. India revealed the prevalence to

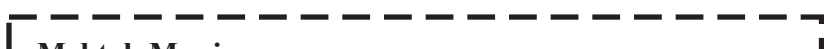

Mehtab Munir

I Senior Lecturer, Department of Pharmacology,

I Bahria University Medical and Dental College, Karachi

I

Khalid Mustafa Memon

Professor, Department of Pharmacology,

I Bahria University Medical and Dental College, Karachi

I Sajid Abbas Jaffri

I Professor and Head, Department of Medicine,

I Bahria University Medical and Dental College, Karachi

I Hasan Ali

I Professor and Head, Department of Biochemistry,

Bahria University Medical and Dental College, Karachi

Received: 10-Aug-2020

Accepted: 07-Dec-2020 be $5.8 \%$ and typically community above 65 years of age was affected. ${ }^{3}$ Among all the joints, knee joint is affected most of all from osteoarthritis. Worldwide 3.8\% of people suffered from knee osteoarthritis in contrast to $0.85 \%$ prevalence of hip osteoarthritis. $2.2 \%$ of males and 3.8\% of females were found to have knee OA in South East Asia. ${ }^{4}$

Progressive and chronic degeneration of articular cartilage and abnormal joint remodeling are hallmark of osteoarthritis, leading to pain and limitation of movement. In synovial joints, whole joint is involved including cartilage, subchondral bone, synovial membrane, ligaments and periarticular musculature. ${ }^{5}$

People suffering from osteoarthritis mostly gain medical consideration for the reason of joint pain that is classically localized around knee and distal femur. With progression in joint degeneration, a steady decline in functional activities and trouble in performing simple daily jobs such as walking, climbing stairs and housekeeping is observed by the patient. Muscle wasting and adhesive capsulitis may occur in knee joint. $^{6}$

Classic radiographic findings are joint space narrowing, sub-chondral bone sclerosis, osteophytes and cyst formation. OA can be divided into five grades (0-4) on plain radiograph according to Kallgren Lawrence grading system. ${ }^{7}$ 
American College of Rheumatology (ACR) has given comprehensive guidelines for knee OA diagnosis. Clinical plus radiographic criteria requires knee pain with 1 of these three findings age $>50$ years, morning stiffness $<30$ minutes and crepitus + presence of osteophytes. ${ }^{8}$

Knee osteoarthritis treatment is categorized into; nonpharmacological, pharmacological and surgical intervention. ${ }^{9}$ Non-steroidal anti-inflammatory drugs (NSAIDs) are corner stone for the pharmacological treatment of osteoarthritis. Naproxen sodium is commonly employed for treatment of knee osteoarthritis. It is an established non-selective NSAIDs and is a prescription drug. ${ }^{10}$ Naproxen non-selectively inhibits both iso-forms of cyclo-oxygenase enzyme. Hence it prevents inflammation in osteoarthritis through inhibition of COX2 enzyme. But it has been found that COX-1 (also known as prostaglandin endoperoxide synthase-1) enzyme is over expressed by synovial cells in OA patients. Naproxen shows more selectivity for COX-1 iso-form. ${ }^{11}$

Although diverse pharmacological modalities are available for management of OA but none of these offer treatment other than symptomatic relief and are associated with many adverse effects. Hence for chronic disease like OA, increasing trend for using alternate medicines has been observed. ${ }^{12}$ Moreover herbal medications are mostly of low cost, widely available and more tolerable. Many patients around the world prefer to use herbal medicine; thereby; it is important to evaluate the efficacy and safety of these herbs. ${ }^{13}$

Scientific name of ginger is Zingerber officinal and rhizome is the part of plant that is commonly used. Ginger is a commonly used spice all over the world with origin from southern China or south-east Asia. ${ }^{14}$ Characteristic pungent flavor of ginger is because of non-volatile molecules like gingerols, shagoals, paradols, and zingerone. The active ingredients in ginger include gingerol and shagoal have antiinflammatory, anti-oxidant and some other pharmacological activities. Mechanism of action is through inhibition of cyclo-oxygenase enzyme, lipo-oxygenase pathway, interleukin- $1 \beta$ (IL-1 $\beta$ ), IL- 6 and tumor necrosis factor- $\alpha$ (TNF- $\alpha$ ). Activation of NF KB and inhibition of inflammatory cell infiltration may also be involved. Ginger has shown to have chondro-protective role in osteoarthritis in animal model. This role is due to its anti-inflammatory and antioxidant activity. ${ }^{15}$

Ginger has analgesic and anti-inflammatory role, moreover it is readily available and commonly used in culinary in Southeast Asia. Hence its acceptance as treatment of osteoarthritis is anticipated to be effortless. Therefore, this study was aimed to evaluate clinical efficacy and safety of ginger with naproxen in comparison with naproxen alone for management of knee osteoarthritis.

\section{METHODOLOGY:}

It was a randomized clinical trial that was conducted in medical OPD of National Medical Center in Karachi from $21^{\text {st }}$ September 2018 till $31^{\text {st }}$ March 2019. The study was approved from ERC of Bahria University Medical and Dental College numbered 49/2018. Sample size was estimated using the method of sample size "Comparing Two Means" on Openepi. Minimum sample sizes in each group was calculated to be $n 1=23, n 2=23$, hence 46 in total. However 60 patients were registered in this study with 30 patients in each group after informed written consent.

Inclusion criteria were; males and females $>50$ years of age suffering from knee osteoarthritis requiring regular medical treatment. Clinical and X-ray findings of the patients were as stated by the American College of Rheumatology criteria for knee osteoarthritis ${ }^{8}$ and radiographic evidence of knee $\mathrm{OA}$ in concordance with Kallgren-Lawrence grade of 1 to 3. ${ }^{7}$ Patients having known history of hypersensitivity to the study drugs, Kallgren-Lawrence grade of 0 or 4, concurrent other inflammatory or traumatic joint disease, recent or concurrent major illness of hepatic, renal, cardiovascular, gastrointestinal, hematopoietic or endocrine systems, terminal illness or cancer, overweight defined as a BMI $>30$, pregnancy or lactation (women) and intra-articular or systemic corticosteroid therapy in 3 months preceding enrolment for the study were excluded from the study.

Patients fulfilling the inclusion criteria were given wash out period of 72 hours for any medication before start of the study. By using simple systematic randomization, these 60 patients were divided into two groups: Group A $(n=30)$ received tablet Naproxen $500 \mathrm{mg}+$ capsule Ginger $550 \mathrm{mg}$ orally twice daily for 6 weeks. Group B $(n=30)$ patients were prescribed tablet Naproxen $500 \mathrm{mg}$ orally twice daily for 6 weeks. A pre-designed evaluation form was used to record demographic profile and study parameters of the patients. The clinical efficacy of the drugs was evaluated by composite Western Ontario and McMaster Universities Osteoarthritis (WOMAC) index and Visual Analogue Scale (VAS) at the beginning and end of the study. ${ }^{7,8}$ WOMAC index evaluates pain and stiffness in knee OA. VAS was used to assess pain at movement. Safety profile of the drugs was assessed by noting the adverse effects like heart burn, epigastric pain, diarrhea, flatulence, abdominal distension, rash, allergic reactions and fluid retention during the study. Statistical analysis was done using SPSS version 23.0. Normality of the data was assessed by plotting histogram. Independent t-test was applied to check difference between the two groups. P-value $<0.05$ was considered as statistically significant.

\section{RESULTS:}

Initially 60 patients were registered for the study with 30 patients in each of the two groups. However 03 patients dropped out in group A and 04 patients in group B failed to follow-up. Hence 53 patients finished the study (group A: $\mathrm{n}=27$ and group $\mathrm{B}: \mathrm{n}=26$ ).

No significant difference was found for demographic 
Mehtab Munir, Khalid Mustafa Memon, Sajid Abbas Jaffri, Hasan Ali

Table 1: Demographic data of patients in group A and group B

\begin{tabular}{|c|c|c|c|}
\hline $\begin{array}{c}\text { Demographic } \\
\text { Variable }\end{array}$ & $\begin{array}{c}\text { Group A }(\mathrm{n}=27) \\
\text { Mean } \pm \text { Standard deviation }\end{array}$ & $\begin{array}{c}\text { Group B }(\mathrm{n}=26) \\
\text { Mean } \pm \text { Standard deviation }\end{array}$ & P-value $\Phi$ \\
\hline Age & $57.07 \pm 4.44$ & $57.03 \pm 4.84$ & 0.97 \\
\hline BMI & $28.07 \pm 1.53$ & $27.71 \pm 1.39$ & 0.33 \\
\hline Gender & & & \multirow{3}{*}{0.77} \\
\hline Females & $21(70 \%)$ & $22(73.3 \%)$ & \\
\hline Males & $9(30 \%)$ & $8(26.7 \%)$ & \\
\hline Involved Knee joi & & & \multirow{3}{*}{0.78} \\
\hline Right knee & $20(66.7 \%)$ & $21(70 \%)$ & \\
\hline Left knee & $10(33.3 \%)$ & $9(30 \%)$ & \\
\hline
\end{tabular}

pindependent t-test

Group A treated with Naproxen + ginger Group B treated with Naproxen

Table 2-A Comparison of the pain scores (VAS) between

group A (Naproxen + ginger) and group B (Naproxen) before and after intervention

\begin{tabular}{|c|c|c|c|}
\hline Intervention & $\begin{array}{c}\text { Mean } \pm \text { Standard } \\
\text { deviation of group A }\end{array}$ & $\begin{array}{c}\text { Mean } \pm \text { Standard } \\
\text { deviation of group B }\end{array}$ & P-value $\boldsymbol{\Phi}$ \\
\hline Before & $5.43 \pm 0.69$ & $5.27 \pm 0.78$ & 0.383 \\
\hline After & $2.48 \pm 0.64$ & $2.92 \pm 0.68$ & 0.019 \\
\hline
\end{tabular}

申independent t-test VAS $=$ visual analogue scale

Table II-B Comparison of WOMAC scores between

group A (Naproxen + ginger) and group B (Naproxen) before and after intervention

\begin{tabular}{|c|c|c|c|}
\hline Intervention & $\begin{array}{c}\text { Mean } \pm \text { Standard } \\
\text { deviation of group A }\end{array}$ & $\begin{array}{c}\text { Mean } \pm \text { Standard } \\
\text { deviation of group B }\end{array}$ & P-value $\boldsymbol{\Phi}$ \\
\hline Before & $36.70 \pm 7.17$ & $36.83 \pm 10.04$ & 0.953 \\
\hline After & $17.17 \pm 4.18$ & $20.12 \pm 4.65$ & 0.020 \\
\hline
\end{tabular}

sindependent t-test

WOMAC score $=$ Western Ontario and McMaster Universities Osteoarthritis index

Table 3 Adverse effects of Patients in group A and group B after 6 weeks of intervention

\begin{tabular}{|c|c|c|}
\hline Adverse effects & $\begin{array}{c}\text { Group A (n=27) } \\
\text { (Percentage \%) }\end{array}$ & $\begin{array}{c}\text { Group B (n=26) } \\
\text { (Percentage \%) }\end{array}$ \\
\hline Heart burn & $3(11.11 \%)$ & $8(30.76 \%)$ \\
\hline Epigastric pain & $0(0 \%)$ & $1(3.84 \%)$ \\
\hline Diarrhea & $6(22.22 \%)$ & $1(3.84 \%)$ \\
\hline Rash & $0(0 \%)$ & $0(0 \%)$ \\
\hline Allergic reaction & $0(0 \%)$ & $0(0 \%)$ \\
\hline
\end{tabular}

Group A treated with Naproxen + ginger

Group B treated with Naproxen

variables such as age, gender, BMI and affected knee in two groups. (Table 1) Before intervention, difference between pain and WOMAC scores of the two groups was not significant ( $\mathrm{p}$-value $>0.05$ ). Means of pain scores were 5.43 \pm 0.69 in group A and $5.27 \pm 0.78$ for group B before intervention. After 6 weeks of intervention means of pain scores decreased in both groups but more in group A (2.48 $\pm 0.64)$ than group B $(2.92 \pm 0.68)(\mathrm{p}$-value $=0.019)$ (Table 2a). Means of WOMAC score were group A; $36.70 \pm 7.17$ and group B $36.83 \pm 10.04$ before intervention. After intervention the scores were also observed to be decreased in group A (17.17 \pm 4.18$)$ and group B (20.12 \pm 4.65$)$ but statistically significant $(\mathrm{p}$-value $=0.020)$ decrease in group A. (Table 2b)

Regarding adverse reactions, it was noted that heart burn was more common in group B $(8 / 26)$ and diarrhea $(6 / 27)$ was observed more in group A. However no significant difference was found in occurrence of adverse effects between the two groups that is $\mathrm{p}$-value $=0.914$. Rash, allergic reactions, abdominal distension or fluid retention were not reported by any of the participants. Eight patient in group B suffered from heart burn and only one had severe epigastric pain at $5^{\text {th }}$ week of the study. (Table 3 ) The patient was advised to stop the regimen at once and was managed accordingly. 


\section{DISCUSSION:}

This study was conducted on 53 patients suffering from primary knee osteoarthritis with age equal and more than 50 years. Percentage of female patients $(71.66 \%)$ was more than males $(28.33 \%)$. This is similar to an Indian study in which females above 50 years $(31.6 \%)$ were found to be suffering from primary knee OA more than males with comparable age (28.1\%). ${ }^{16} \mathrm{~A}$ study conducted in Sri Lanka also demonstrated that knee OA was more prevalent in females above 50 years of age $(20.1 \%) .{ }^{17}$ In this study most of the patients were overweight (mean BMI > 25). The similar results were found in the Indian study where primary knee OA was more common in overweight/ obese as compared to normal or underweight people. ${ }^{16}$

The present study patients of knee osteoarthritis were randomized to group A and group B. Baseline pain (VAS) and WOMAC scores were noted before intervention and showed no significant difference between the groups. After receiving 6 weeks of intervention both pain and WOMAC scores of the participants showed decline but it was more in group A ( $p$-value $>0.05$ ). Gastrointestinal adverse effects were more in both groups but no significant difference was found between the groups. Notable adverse effect in group A was diarrhea but that was mild in nature (1-2 episodes of loose stools / day) and did not lead to quitting the study.

A similar study was conducted in $\operatorname{Iran}^{18}$ on 90 patients of knee OA for 12 weeks to assess effect of ginger on pain and satisfaction of the patients. Randomization was done to divide the patients into ginger and control groups. The ginger group participants took osteoarthritis treatment prescribed by orthopedic specialist and ginger with the dose of $1000 \mathrm{mg}$ / day (2 tablets of $500 \mathrm{mg}$ ). The control group only took treatment given by the orthopedic specialist. A decline in pain scores (VAS) was observed in both groups but more in the ginger group ( $p$-value $=0.001)$. Adverse effects were found to be same in both groups and were more related to gastrointestinal tract similar to our study. ${ }^{18}$

Another study was conducted in India on 60 patients of knee OA. The patients were divided into 3 groups. Group I was given tablet diclofenac $50 \mathrm{mg}$ and capsule placebo, group II received capsule ginger $750 \mathrm{mg}$ and capsule placebo and group III was given capsule ginger $750 \mathrm{mg}$ and tablet diclofenac $50 \mathrm{mg}$. The patients were assessed fortnightly till 12 weeks. Group III demonstrated marked improvement in WOMAC index and VAS as compared to other groups (p- value $<0.001$ ). Regarding adverse effects, no significant variation was seen among the groups that was in accordance with the present study. ${ }^{19}$

A meta-analysis was conducted by Osteoarthritis Research Society International (OARSI) conducted a meta-analysis in $2015 .{ }^{20}$ Objective was to assess efficacy and safety of ginger in osteoarthritis. This meta-analysis included randomized placebo controlled trials with duration ranging from 3 to 12 weeks. 47 to 66 years was mean age of participants with higher percentage of women. The daily dose of ginger ranged from $500 \mathrm{mg}$ to $1000 \mathrm{mg}$. A statistically significant decline in pain ( $\mathrm{p}$-value $=0.005)$ and disability ( $p$-value $=0.01$ ) was caused by ginger. Moreover no serious events were noted with ginger. Hence ginger was concluded to be efficacious and safe for reducing pain and inflammation of OA. ${ }^{20}$

This anti-inflammatory and analgesic effect of ginger is because of decline in pro-inflammatory cytokine as demonstrated by a double-blinded randomized placebocontrolled clinical trial. The patients were given 500mg capsules of ginger twice daily (GG) or placebo (PG) containing starch. Serum of participants was collected before and after administration of ginger. A significant decline in serum nitrous oxide and hs-C protein was observed in GG group. ${ }^{21}$ In this study, tumor necrosis factor- $\alpha(\mathrm{TNF}-\alpha)$ and interleukin-1 $\beta$ (IL-1 $\beta$ ) were also compared before and after administration of ginger or placebo. These parameters were also found to be less in ginger group as compared to group receiving placebo after 3 months of period. ${ }^{22}$ Inhibition of several other inflammatory markers by ginger e.g. leukotrienes and prostaglandins, have also been shown in other studies. ${ }^{23,24}$

Limited evidence is available to observe the effect of ginger on knee osteoarthritis. Hence future multicenter and long term studies are recommended.

\section{CONCLUSION:}

Ginger is more effective in reducing pain and stiffness in management of knee osteoarthritis when given with naproxen as compared to naproxen alone.

Authors Contribution:
Mehtab Munir: Designing the study, data collection, data I
analysis, literature search and article write up
Khalid Mustafa Memon: Designing the study, article write |
I up and proof reading
Sajid Abbas Jaffri: Data collection, article write up and proof |
I Hading
I Iasan Ali: Literature search, article write up and proof reading

\section{REFERENCES:}

1. Mobasheri A, Bay-jensen A, van Spil WE, Larkin J, Levesque MC. Osteoarthritis Year in Review 2016?: biomarkers ( biochemical markers ). 2017;25(2):199-208. doi: 10.1016/j. joca.2016.12.016.

2. WHO / chronic rheumatic conditions. Available from http:// www.who.int/chp/topics/rheumatic/en/ (cited on 15 July 2019).

3. Akhter E, Bilal S, Kiani A, Haque U. Prevalence of arthritis in India and Pakistan: A review. Rheumatol Int. 2011; 31(7) :849-855.

4. Cross M, Smith E, Hoy D, Nolte S, Ackerman I, Fransen M, et al. The global burden of hip and knee osteoarthritis: Estimates from the Global Burden of Disease 2010 study. Ann Rheum Dis. 2014;73(7):1323-1330. 
5. Rahmati M, Mozaffri M. The Association between Osteoarthritis and Osteoporosis: In Bad Company? J Osteopor Phys. 2015; 3(2):134-139.

6. La Porta C, Bura SA, Negrete R, Maldonado R. Involvement of the endocannabinoid system in osteoarthritis pain. Eur $\mathrm{J}$ Neurosci. 2014;39(3):485-500.

7. Alshami AM. Knee osteoarthritis related pain?: a narrative review of diagnosis and treatment. Int J Health Sci. 2014; 8(1):85-104.

8. Pereira D, Ramos E, Branco J. Osteoarthritis. Acta Med Port, 2015; 28(1): 99-106.

9. McAlindon TE, Bannuru RR, Sullivan MC, Arden NK, Berenbaum F, Bierma-Zeinstra SM, et al. OARSI guidelines for the non-surgical management of knee osteoarthritis. Osteoarthr Cartil. 2014; 22(3):363-388.

10. Sanders D, Krause K, O'Muircheartaigh J, Thacker MA, Huggins JP, Vennart W, etal. Pharmacologic modulation of hand pain in osteoarthritis: A double blind placebo-controlled functional magnetic resonance imaging study using naproxen. Arthri \& Rheumatol. 2015; 67(3): 741-751.

11. Wang C, Wang F, Lin F, Duan X, Bi B. Naproxen attenuates osteoarthritis progression through inhibiting the expression of prostaglandin-endoperoxide synthase 1. J Cell Physiol. 2019; 234 (8): 12771-12785.

12. Therkleson T. Topical ginger treatment with a compress or patch for osteoarthritis symptoms. J Holist Nurs. 2014; 32(3)173-182.

13. Farzaei MH, Farzaei F, Gooshe M, Abbasabadi Z, Rezaei N, Abdolghaffari AH. Potentially effective natural drugs in treatment for the most common rheumatic disorder: osteoarthritis. Rheumatol Int. 2015; 35(5):799-814.

14. Tanaka K, Arita M, Sakurai H, Ono N, Tezuka Y. Analysis of Chemical Properties of Edible and Medicinal Ginger by Metabolomics Approach. Biomed Res Int. 2015; 14(1): 11551162. doi: 10.1155/2015/671058.

15. Aborehab NM, El Bishbishy MH, Refaiy A, Waly NE. A putative Chondroprotective role for IL-1 â and MPO in herbal treatment of experimental osteoarthritis. Alt Med.2017; 17(1): 495-504.
16. Pal CP, Singh P, Chaturvedi S, Pruthi KK, Vij A. Epidemiology of knee osteoarthritis in India and related factors. Ind J Orthop. 2016; 50(5): 518-522.

17. Prashansanie Hettihewa A, Gunawardena NS, Atukorala I, Hassan F, Lekamge IN, Hunt DJ. Prevalence of knee osteoarthritis in a suburban, Srilankan, adult female population: a population-based study. Int J Rheum Dis. 2018; 21(2): $394-$ 401. doi: 10.1111/1756-185X.13225.

18. Alipour Z, Asadizaker M, Fayazi S, Yegane N, Kochak M, Hossein M, et al. The Effect of Ginger on Pain and Satisfaction of Patients with Knee Osteoarthritis. Jundishapur J Chronic Dis Care. 2017; 6(1) e34798. doi: 10.17795/jjcdc-34798.

19. Paramdeep G. Efficacy and tolerability of ginger (Zingiber officinale) in patients of osteoarthritis of knee. Indian J PhysiolPharmacol. 2013; 57(2):177-183.

20. Bartels EM, Folmer VN, Bliddal H, Altman RD, Juhl C, Tarp $\mathrm{S}$, et al. Efficacy and safety of ginger in osteoarthritis patients: A meta-analysis of randomized placebo-controlled trials. Osteoarthr Cartil .2015; 23(1):13-21.

21. Naderi Z, Mozaffari-khosravi H, Dehghan A, Nadjarzadeh A, Huseini HF. Effect of ginger powder supplementation on nitric oxide and C-reactive protein in elderly knee osteoarthritis patients: A 12-week double-blind randomized placebocontrolled clinical trial. J Tradit Complement Med. 2016; 6(3): 199-203.

22. Mozaffari-khosravi H, Naderi Z, Dehghan A, Nadjarzadeh A, Huseini HF. Effect of Ginger Supplementation on Proinflammatory Cytokines in Older Patients with Osteoarthritis?: Outcomes of a Randomized Controlled Clinical Trial. J Nutr Gerontol Geriatr. 2016; 35(3): 209-218.

23. Srinivasan K. Ginger rhizomes (Zingiber officinale ): A spice with multiple health beneficial potentials. Phar Nutri. 2017; 5(1):18-28. doi: 10.1016/j.phanu.2017.01.001.

24. Vaishya R, Agarwal AK, Shah A, Vijay V, Vaish A. Current status of top 10 nutraceuticals used for Knee Osteoarthritis in India. J Clin Orthop Trauma. 2018; 9 (4): 338-348. 